\title{
Effects of thyroid diseases on pregnancy outcomes
}

\author{
MIN ZHOU $^{1 *}$, MIN WANG $^{1 *}$, JUMING LI $^{1,2}$, XIAOHUI LUO $^{1}$ and MINXIANG LEI ${ }^{1}$ \\ ${ }^{1}$ Department of Endocrinology, Xiangya Hospital, Central South University, Changsha, Hunan 410008; \\ ${ }^{2}$ Department of Endocrinology, Tianjin Fifth Central Hospital, Tianjin 300450, P.R. China
}

Received November 15, 2017; Accepted June 22, 2019

DOI: $10.3892 /$ etm.2019.7739

\begin{abstract}
The current study aimed to analyze the effects of thyroid diseases on pregnancy outcomes and investigate the effects of levothyroxine (L-T4) tablets in the treatment of hypothyroidism. The current study determined the prevalence of thyroid diseases using two diagnostic criteria, the prevalence of thyroid diseases among pregnant women recruited in 2010 and 2014 were initially determined by the 2011 Guidelines of the American Thyroid Association for the Diagnosis and Management of Thyroid Disease During Pregnancy and Postpartum (2011 ATA Guidelines). Subjects were categorized into six groups: Normal, hypothyroxinemia, hypothyroidism, subclinical hypothyroidism $(\mathrm{SCH})$, hyperthyroidism and subclinical hyperthyroidism. L-T4 was administered in the thyroid-insufficient groups and the prevalence rates of these categories were obtained using the diagnostic criteria from the 2011 ATA Guidelines and the 2012 Chinese Guidelines for the Diagnosis and Treatment of Thyroid Disease During Pregnancy and Postpartum (2012 Chinese Guidelines). The results of the current study demonstrated that the screening of thyroid function was significantly increased in 2014 (thyroid dysfunction rate, $82.4 \%$ vs. 29.1\%; $\mathrm{P}<0.001$ ). Hypothyroxinemia, hypothyroidism, $\mathrm{SCH}$, hyperthyroidism and subclinical hyperthyroidism increased the likelihood of certain adverse outcomes and complications. L-T4 decreased the odds of gestational hypertension, premature birth and low birth weight or very low birth weight in the hypothyroidism group. A statistically significant difference was identified between thyroid disease incidences as determined by the 2011 ATA Guidelines 2012 Chinese Guidelines. In conclusion, abnormal thyroid levels increased the odds of adverse pregnancy outcomes, L-T4 administration improved pregnancy outcomes and the 2012 Chinese Guidelines may provide a
\end{abstract}

Correspondence to: Dr Min Zhou, Department of Endocrinology, Xiangya Hospital, Central South University, 87 Xiangya Road, Changsha, Hunan 410008, P.R. China

E-mail: xyzm3639@163.com

${ }^{*}$ Contributed equally

Key words: pregnancy complications, pregnancy outcomes, thyroid diseases, thyroxine better reference for Chinese pregnant women with subclinical hyperthyroidism.

\section{Introduction}

Thyroid diseases, which include hypothyroxinemia, hypothyroidism, subclinical hypothyroidism ( $\mathrm{SCH}$ ), hyperthyroidism and subclinical hyperthyroidism, are the second most common endocrine diseases during pregnancy $(1,2)$. Thyroid diseases during pregnancy have been studied extensively in endocrinology, obstetrics and gynecology (3-5). Vulsma et al (6) identified that thyroid hormones exist in umbilical blood from mothers with thyroid hormone synthesis deficiency, suggesting that free thyroxine (free T4 or fT4) is delivered through the placenta. Maternal thyroid hormones serve essential roles in fetal brain development (gestational week 1-20) (7). Thyroid diseases during pregnancy severely affect pregnancy outcomes and neuropsychological development of the offspring $(8,9)$. Alterations in the secretion of thyroid stimulating hormone (TSH) or an increase in serum T4 levels result in fetal neurodevelopmental defects $(10,11)$.

In early pregnancy, thyroid synthesis deficits (hypothyroidism, $\mathrm{SCH}$ and hypothyroxinemia) and positive thyroid antibodies are associated with impaired intelligence and motor skills $(12,13)$. By contrast, certain studies have demonstrated that subclinical hyperthyroidism does not affect pregnancy outcomes (14-16). According to the Guidelines of the American Thyroid Association for the Diagnosis and Management of Thyroid Disease During Pregnancy and Postpartum in 2011 (2011 ATA Guidelines) (17) and 2012 Chinese edition of Thyroid Nodules and Differentiated Thyroid Cancer Management Guidelines (2012 Chinese Guidelines) $(18,19)$, levothyroxine (L-T4) should be administrated to pregnant women with $\mathrm{SCH}$ who are thyroid peroxidase antibody-positive. Several studies, however, have claimed that it is not necessary to correct $\mathrm{SCH}$ and isolated hypothyroxinemia $(20,21)$. Therefore, it is not clear whether L-T4 is beneficial in thyroid insufficiency.

A comprehensive study to compare different thyroid levels in pregnant women is lacking. It is not clear whether a Chinese-specific diagnosis of thyroid dysfunction is necessary. Since 2012, a new screening standard based on new Chinese guidelines began to be used and, therefore, two cohorts were recruited in 2010 and 2014 to evaluate the impact of the change in screening standards. The ultimate goal of the current study was to determine thyroid dysfunction in pregnancy in China 
and evaluate the effects of an L-T4 supplement on the outcomes and complications.

\section{Patients and methods}

Study subjects. A total of 3,501 pregnant women were enrolled into the present study from the Department of Obstetrics, Xiangya Hospital (Changsha, China) between August and December 2010 (named Cohort 2010; n=825), and between August and December 2014 (named Cohort 2014; n=2,676). In order to evaluate the impact of the change in screening standards following the publication of the 2012 Chinese Guidelines, 1,037 patients in the cohort of 2014 (Matched Cohort 2014) were selected based on age and weight to be compared with all 825 patients from Cohort 2010 (Table I). In order to evaluate the outcomes of pregnancy and treatment, other analyses were performed on subjects selected and enrolled from cohort 2014. The enrollment criteria for these subjects included: i) Singleton pregnancy, ii) aged between 20 and 42 years old, iii) thyroid function examined during the pregnancy. The exclusion criteria included: i) Not singleton pregnancy (confirmed by ultrasound); ii) aged $<20$ or $>42$ years old; iii) conditions prior to pregnancy, including diabetes, hypertension, seizure or other convulsive disorders, pituitary or adrenal diseases, cancer, severe gastrointestinal diseases, blood system disorders, cerebrovascular diseases, cardiopulmonary dysfunction and infection; iv) autoimmune diseases, including systemic lupus erythematosus, antiphospholipid antibody syndrome and Sjogren's syndrome; v) endocrine diseases prior to pregnancy, including polycystic ovary syndrome and hyperprolactinemia; vi) acute diseases during pregnancy, including appendicitis, pancreatitis and a decrease of whole blood cells; and vii) history of the use of amiodarone or immunosuppressive agents, a history of iodine examinations and radiotherapy within 6 months. The current study was approved by the Institutional Review Board of Central South University (Changsha, China) and designed according to the 2011 ATA Guidelines (17) and 2012 Chinese Guidelines $(18,19)$. All patients provided written informed consent.

Study groups and treatment. For the evaluation of thyroid dysfunction, cohort 2010 and matched cohort 2014 were studied. According to the 2011 ATA Guidelines, patients from all cohorts were divided into the thyroid disease group $(n=132$ in cohort $2010 ; n=539$ in matched cohort $2014 ; n=1,423$ in cohort 2014) and the control/healthy group $(n=693$ in cohort 2010, $n=498$ in matched cohort 2014 and $n=1,253$ in cohort 2014). The control groups included healthy pregnant women with normal thyroid function while the thyroid disease groups included patients with hypothyroxinemia, hypothyroidism, $\mathrm{SCH}$, hyperthyroidism and subclinical hyperthyroidism (Fig. 1).

L-T4 (China Associate Pharmaceutical) was administered orally in selected subjects at an initial dose of $1.5-2.5 \mu \mathrm{g} / \mathrm{kg}$ per day. The dose was then adjusted to $<1.5-2.5 \mu \mathrm{g} / \mathrm{kg}$ per day to ensure serum TSH levels were within the normal range ( $<3 \mathrm{mIU} / 1)$. All L-T4 treatments were administered to patients within the 2 nd and/or 3rd trimester(s). For the evaluation of L-T4 treatment and comparison of pregnancy outcomes, the total 1,423 patients from cohort 2014 with thyroid disease were divided into a treatment group $(n=231)$ and a non-treatment group $(n=1,192)$. Of the 1,192 non-treated patients, 1,111 were divided into 6 different groups $[(n=513)$ normal, $(n=379)$ hypothyroxinemia, $(n=108)$ hypothyroidism, $(n=96) \mathrm{SCH}$, $(n=6)$ hyperthyroidism and $(n=9)$ subclinical hyperthyroidism] and the remaining 81 cases did not deliver at the end of the study due to abortion, induction, miscarriage or other reasons (Table II). To evaluate the effects of L-T4 administration, pregnancy outcomes were compared between three L-T4 treatment subgroup ( $n=92$ in hypothyroidism; $n=29$ in $\mathrm{SCH} ; \mathrm{n}=74$ in hypothyroxinemia) and the corresponding non-treatment subgroup ( $\mathrm{n}=108$ in hypothyroidism; $\mathrm{n}=96$ in $\mathrm{SCH}$; $\mathrm{n}=379$ in hypothyroxinemia).

Clinical guidelines for diagnosis. The ATA developed clinical guidelines on the diagnosis and treatment of thyroid disease during pregnancy and the postpartum period in order to provide evidence-based recommendations to inform clinical decision-making. These guidelines from ATA were first published in 2011 (17) and recently updated in 2017 (22) since significant clinical and scientific advances have occurred in the field. The task force that produced these guidelines consisted of international experts in the field of thyroid disease and pregnancy, as well as international representatives including the Asia and Oceania Thyroid Association. Furthermore, the 2012 Chinese Guidelines suggested that high TSH and fT4 levels were important reassessment markers; thus, these markers were included in the present study to ensure widespread acceptance and adoption of the developed guidelines for Chinese patients.

Thyroid hormone laboratory measurement. The analytical evaluation of the novel electro-chemiluminescent immunoassays was performed for the in vitro quantitative determination of TSH (cat. no. 11731459) and fT4 (cat. no. 12017709) using the Elecsys 2010 immunoassay system (Roche Diagnostics, Basel, Switzerland). The results indicated normal TSH and fT4 values in healthy individuals (97.5\% Confidence Intervals): TSH (0.27-4.2 mIU/l), fT4 (12-22 pmol/1; P5 (5.0th percentile) $=12.87$ pmol/1, P10 (10.0th percentile) $=13.64 \mathrm{pmol} / \mathrm{l})$. According to the 2011 ATA Guidelines, the normal ranges of TSH levels were as follows: Trimester 1, 0.1-2.5 mIU/1; trimester 2, 0.2-3.0 mIU/1; trimester 3, 0.3-3.0 mIU/1; while according to the 2017 ATA Guidelines, the maximum value in all three trimesters increased to $4.0 \mathrm{mIU} / 1$. The normal range of fT4 in the current study was based on the 2011 ATA Guidelines for the healthy population (12.0-22.0 pmol/1 for all three trimesters). By contrast, the normal ranges, according to the 2012 Chinese Guidelines, were even higher: 0.05-5.17, 0.39-5.22 and 0.60-6.84 mIU/1 for TSH in the three trimesters, respectively; and 12.91-22.35, 9.81-17.26 and 9.12-15.71 pmol/1 for fT4 in the three trimesters, respectively.

Diagnostic criteria for thyroid diseases during pregnancy. Screening for thyroid dysfunction was performed based on thyroid function tests, including assays for TSH and fT4 as aforementioned. The normal ranges from either the ATA or Chinese Guidelines were used. Patients were diagnosed as follows: Hypothyroxinemia: TSH within the normal range, fT4<P5 (5.0th); hypothyroidism: TSH>upper limit (97.5th) 
Table I. Demographic information in cohort 2010 and matched cohort 2014.

\begin{tabular}{lcccc}
\hline Characteristic & $\begin{array}{c}\text { Cohort 2010 } \\
(\mathrm{n}=825)\end{array}$ & $\begin{array}{c}\text { Matched cohort 2014 } \\
(\mathrm{n}=1,037)\end{array}$ & $\begin{array}{c}\text { P-value } \\
\text { (2010 vs. matched 2014) }\end{array}$ & Cohort 2014 \\
\hline Age (years) & $29.1 \pm 4.9$ & $29.9 \pm 4.9$ & 0.001 & $29.7 \pm 4.2$ \\
Weight (kg) & $65.8 \pm 10.4$ & $67.8 \pm 10.4$ & $<0.001$ & $66.3 \pm 12.2$ \\
Thyroid dysfunction rate (\%) & 29.1 & 82.4 & $<0.001$ & 78.2 \\
\hline
\end{tabular}

The age and weight were expressed as mean \pm standard deviation.

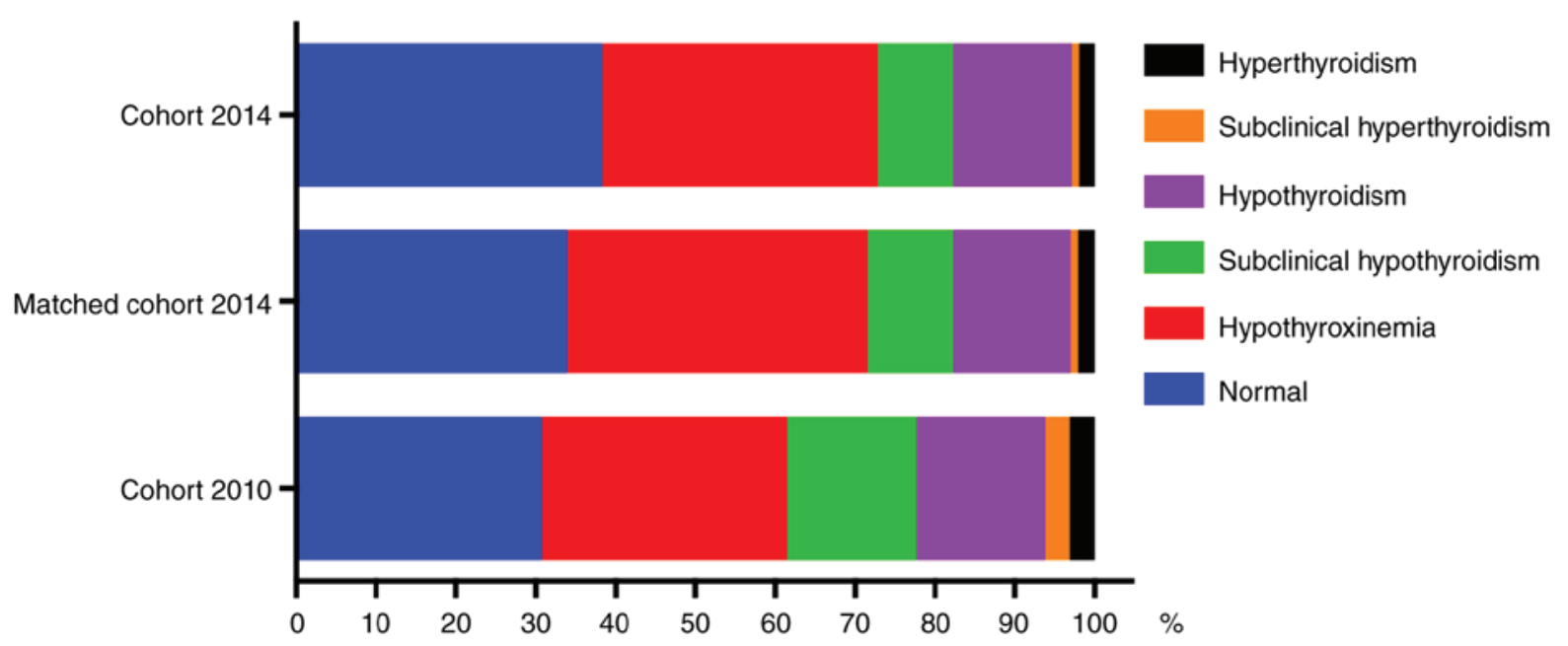

Figure 1. Percentage of thyroid diseases in pregnant subjects from cohort 2010, matched cohort 2014 and cohort 2014.

or TSH $>10 \mathrm{mIU} / 1$ and fT4<lower limit (2.5th); SCH: upper limit< $<$ TSH $\leq 10 \mathrm{mIU} / \mathrm{l}$; hyperthyroidism: TSH<lower limit, fT4>upper limit and no syndrome of gestational hyperthyroidism; subclinical hyperthyroidism: TSH<lower limit and fT4 within the normal range. According to the previously published analysis method (23), one value (the most recent or the worst) was collected for each subject despite the number of thyroid function exams conducted.

Gestational stages were set from the date of the last period and verified by ultrasounds; the trimesters were as follows: Trimester 1, prior to 12 weeks; trimester 2, between 13 and 27 weeks; trimester 3 , between 28 weeks and delivery. Complications [gestational diabetes, gestational hypertension, intrahepatic cholestasis of pregnancy (ICP)] and adverse outcomes [premature birth, very low birth weight (VLBW), low birth weight (LBW), birth asphyxia, fetal distress, premature rupture of membranes (PROM), placental abruption, miscarriage, fetal malformation, mortality] were diagnosed according to the 2010 and 2014 Obstetrics and Gynecology and Pediatrics Guidelines, as described previously $(24,25)$.

Statistical analysis. SPSS software (version 17.0; SPSS, Inc., Chicago, IL, USA) was used to perform statistical analyses and values were presented as mean \pm standard deviation (SD). When the variable distribution of the quantitative data was normal, the mean values of multiple groups were compared using one-way analysis of variance followed by the Tukey's Honest Significant Difference post hoc test. For the categorical data, the Chi-square test or Fisher's exact test (sample size $<5$ ) was used. The Odds Ratio and 95\% Confidence Intervals were calculated using the binary variable regression analysis. Cohen's kappa coefficient (kappa value) was generated to measure the inter-rater agreement between the percentages of patients with thyroid disease in accordance with the two guidelines. $\mathrm{P}<0.05$ was considered to indicate a statistically significant difference.

\section{Results}

Different thyroid levels results in various outcomes. The age, weight and incidence of thyroid disorder were compared in the cohort 2010 and matched cohort 2014 groups (Table I). In past decades, an increasing proportion of women exhibit delayed childbearing for educational, social and economic reasons $(26,27)$, which could explain the advanced maternal age observed in the 2014 matching cohort compared with the 2010 cohort. The mean weight of the patients was also significantly increased in matched cohort 2014, which is likely due to the association between age and weight $(28,29)$. Thyroid function was screened by measuring serum TSH and fT4 levels and the screening rates was significantly increased in matched 2014 cohort (Table I). The incidence of thyroid disorders including $\mathrm{SCH}$, hypothyroidism, subclinical hyperthyroidism and hyperthyroidism were decreased in cohort 2014 or matched cohort 2014 as compared with cohort 2010 (Fig. 1). No significant differences were identified in the number of 


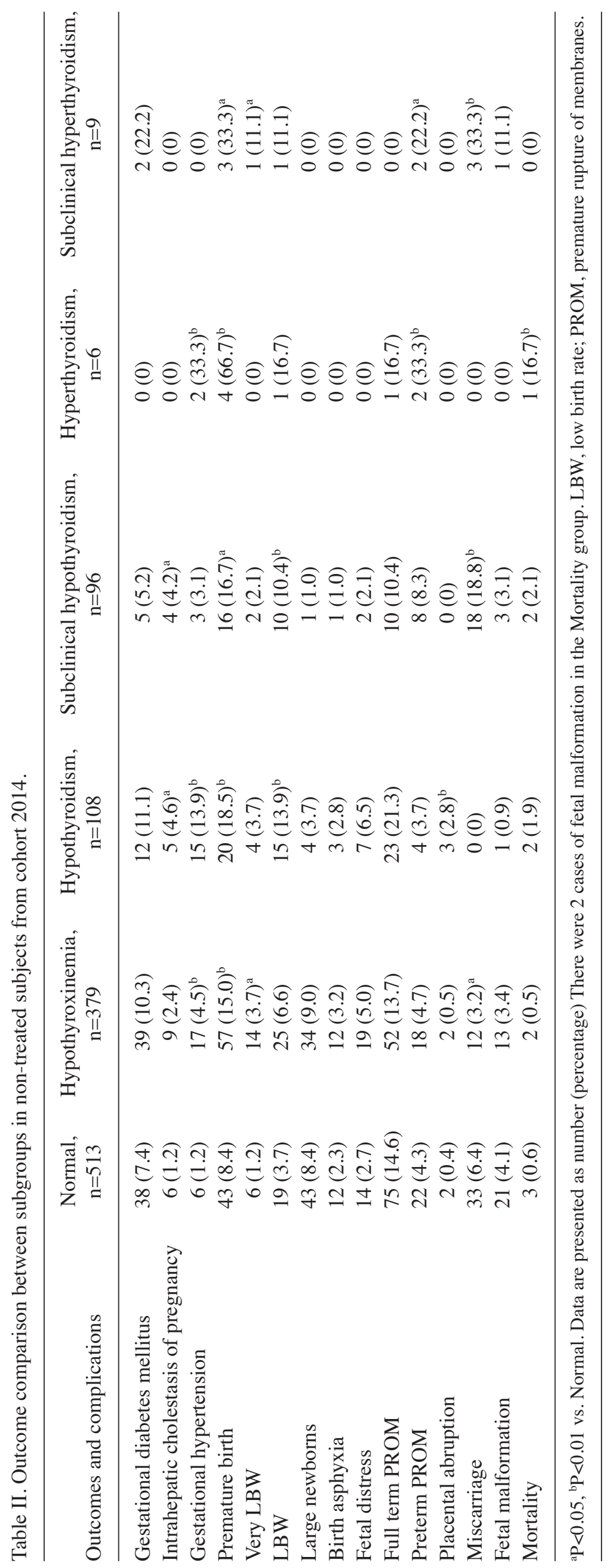


Table III. Outcome comparison between L-T4 treatment group and non-treatment group from cohort 2014.

\begin{tabular}{lccc}
\hline Outcomes and complications & Hypothyroxinemia, $\mathrm{n}=74$ & Hypothyroidism & Subclinical hypothyroidism \\
\hline $\begin{array}{l}\text { Subject number } \\
\text { (treatment vs. non-treatment group) }\end{array}$ & $74 \mathrm{vs.379}$ & 92 vs. 108 & 29 vs. 96 \\
$\begin{array}{l}\text { Gestational hypertension } \\
\text { [Odd Ratio (minimum-maximum)] }\end{array}$ & $0.59(0.13-2.62)$ & $0.209(0.059-0.75)^{\mathrm{b}}$ & - \\
$\begin{array}{l}\text { Premature birth } \\
\text { [Odd Ratio (minimum-maximum)] }\end{array}$ & $0.020(0.005-0.085)^{\mathrm{b}}$ & $0.253(0.091-0.70)^{\mathrm{b}}$ & $0.37(0.080-1.72)$ \\
$\begin{array}{l}\text { LBW or very LBW } \\
\text { [Odd Ratio (minimum-maximum)] }\end{array}$ & $0.019(0.003-0.15)^{\mathrm{a}}$ & $0.327(0.13-0.88)^{\mathrm{a}}$ & - \\
\hline
\end{tabular}

${ }^{\mathrm{a}} \mathrm{P}<0.05,{ }^{\mathrm{b}} \mathrm{P}<0.01$ vs. the non-treatment group. LBW, low birth rate.

pregnancies, number of deliveries, smoking and drinking between the non-treatment groups (data not shown). However, the proportion of caesarean sections was significantly higher in the hypothyroxinemia group compared with the normal group (data not shown).

Patients from cohort 2014 were stratified into various subgroups with different thyroid abnormalities. The outcomes of pregnancy and complications were compared between subgroups in the non-treatment group from cohort 2014. Several outcomes and complications were significantly different in thyroid disorder subgroups as compared with the normal subgroup (Table II). The abnormal outcomes of pregnancy and complications included ICP, gestational hypertension, premature birth, VLBM, LBM, preterm PROM, miscarriage, placental abruption and mortality. However, no significant differences were identified in gestational diabetes mellitus (GDM), large newborns, birth asphyxia, birth distress, full-term PROM and fetal malformation between the two groups.

L-T4 administration reduces the odds of adverse outcomes. To analyze the effects of L-T4 treatment on patients with thyroid hormone deficiencies, 231 subjects from the hypothyroidism, SCH and hypothyroxinemia groups in cohort 2014 were treated with L-T4; the effects were compared with the non-treatment group. L-T4 significantly reduced the odds of premature birth, and LBW or VLBW in newborns in the hypothyroxinemia group (Table III). L-T4 also significantly decreased the odds of gestational hypertension, premature birth and LBW or VLBW in newborns in the hypothyroidism group.

Following this, the treatment group in cohort 2014 were divided into two subgroups based on the thyroid levels following L-T4 administration: Regular and Irregular. The irregular subgroup was defined as having thyroid hormone levels not within the regular range, according to the 2011 ATA Guidelines. In $41(21.03 \%)$ of the total 195 patients from three subgroups (Hypothyroidism, SCH and Hypothyroxinemia), thyroid hormone levels returned to regular following treatment with L-T4 (Table IV). No significant differences in pregnancy outcomes and complications were identified between the normal and abnormal thyroid groups following treatment. It was revealed that the odds of GDM occurring in patients from the SCH subgroup was significantly increased compared with normal subjects (23.5 vs. $7.4 \%$ ). No differences in pregnancy outcomes and complications were observed in patients from the other subgroups, regardless of their thyroid hormone levels.

Two guidelines provide different diagnostic criteria for thyroid diseases. Thyroid diseases were diagnosed according to the 2011 ATA and 2012 Chinese Guidelines following the measurement of serum TSH and fT4 levels. In $0.73 \%$ of patients, fT4 levels were higher than the cutoff values (data not shown). The percentage of patients diagnosed with hypothyroxinemia, hypothyroidism and $\mathrm{SCH}$ significantly increased when the 2011 ATA Guidelines were used compared with the 2012 Chinese Guidelines (Table V). The percentage of normal subjects and patients diagnosed with subclinical hyperthyroidism was significantly decreased when the 2011 ATA Guidelines were used compared with the 2012 Chinese Guidelines.

The number of diagnoses of thyroid dysfunction during pregnancy was compared when using the 2011 ATA and 2012 Chinese Guidelines. It was demonstrated that the numbers of diagnoses made in the three trimesters with the two guidelines were significantly different and that trimester 1 had the highest accordance rate (Table VI). The accordance rate was calculated by subtracting number of cases that received same diagnoses in both guidelines from the total case number. Similar analysis was conducted in the healthy, hypothyroxinemia, hypothyroidism, SCH and subclinical hyperthyroidism groups (data not shown). The two guidelines resulted in different prevalence rates in all the comparisons.

\section{Discussion}

Comprehensive experiments were performed to evaluate the effects of TSH levels on pregnancy outcomes and complications in China (30-32). The current study indicated that when pregnancy is compounded by thyroid disorders including hypothyroidism, $\mathrm{SCH}$ and hyperthyroidism, the potential for maternal and fetal adverse outcomes increases. Hypothyroxinemia and subclinical hyperthyroidism significantly increases adverse pregnancy outcomes and complications (7). Furthermore, L-T4 administration in thyroid deficiency groups may improve pregnancy outcomes and decrease the odds of complications (33). 


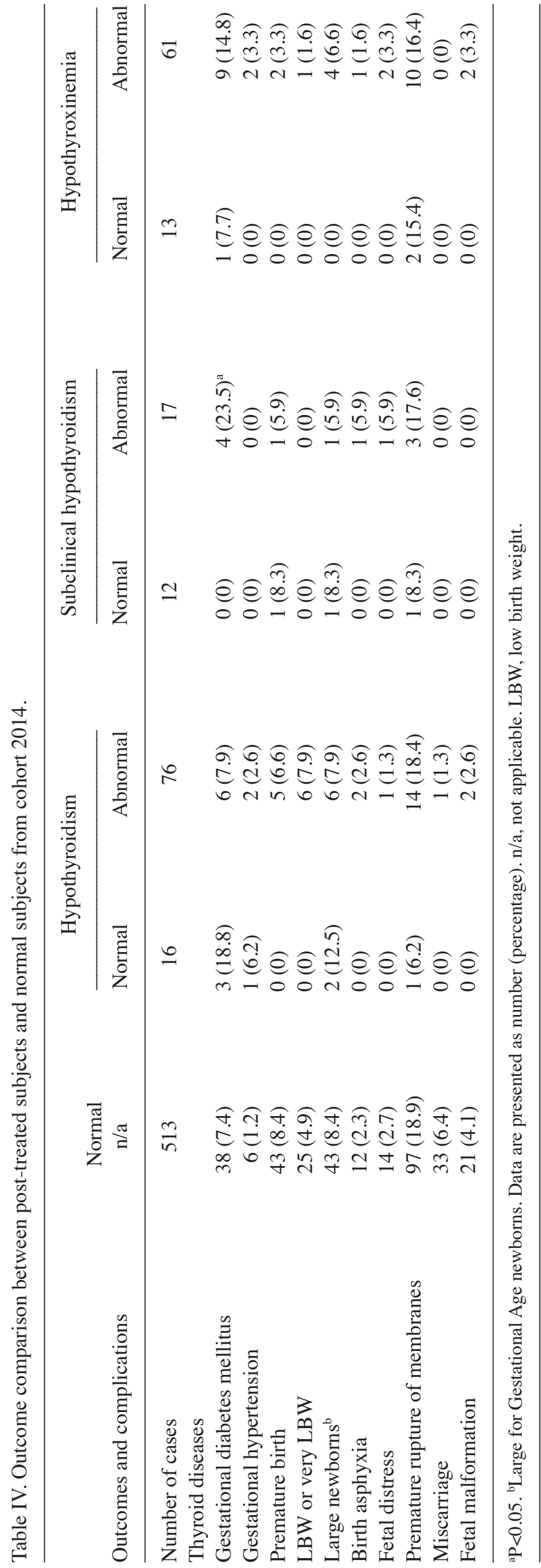

Proper diagnosis of thyroid dysfunction during pregnancy is essential because maternal thyroid diseases complicate pregnancy $(1,2)$. Therefore, accurate diagnosis guidelines may provide cutoff values to correctly diagnose thyroid diseases, allowing appropriate clinical interventions. The metabolism and hormone levels of pregnant women are different from those in non-pregnant women $(34,35)$; therefore, it is not appropriate to use generalized guidelines to detect thyroid diseases during pregnancy. However, it is not clear which guidelines should be applied in China for pregnant patients. The current study compared the 2011 ATA Guidelines and the 2012 Chinese Guidelines. It was demonstrated that the two guidelines produced different thyroid function screening rates in all thyroid diseases through the entire gestational period. As the TSH reference values are relatively high in the 2012 Chinese Guidelines, more focus should be given to diagnose $\mathrm{SCH}$ in early and late pregnancy.

Thyroid hormones are essential for fetal brain development, and thyroid abnormalities adversely affect offspring neuropsychological development $(10,14,34)$. Thyroid disorders result in premature birth, gestational hypertension, fetal mortality and other severe adverse outcomes (36-38). Therefore, it is necessary to screen thyroid function during early pregnancy. Thyroid diseases, including hypothyroxinemia, hypothyroidism, $\mathrm{SCH}$, hyperthyroidism and subclinical hyperthyroidism, are associated with increased risks of maternal and fetal complications $(8,10,14,21)$. However, whether all the aforementioned thyroid conditions are associated with similar pregnancy outcomes or newborn abnormalities have not been studied previously. The results of the present study demonstrated that various thyroid levels complicate pregnancy and fetal development. The comprehensive data from the present study included various pregnancy complications during different trimesters. The inconsistencies in the impact of subclinical hyperthyroidism and hyperthyroidism in cohort 2014 compared with other studies may be due to the small sample size ( 9 and 6 cases) $(8,39,40)$.

The treatment of $\mathrm{SCH}$ and hypothyroxinemia is a debated topic. Administration of L-T4 is beneficial according to certain studies (41-43), whereas potentially serious and under-recognized drug interactions can be harmful and dangerous (44). In addition, studies claimed that treatment with L-T4 did not cause a significant difference in offspring development $(45,46)$. L-T4 decreased the number of patients with thyroid deficiency also having gestational hypertension, LBW or VLBW babies, premature births and miscarriage, which is consistent with previously published studies $(46,47)$. Therefore, the L-T4 administration protocols can be applied in obstetrics departments in patients with similar thyroid disorders. Multiple variable analyses confirmed that L-T4 supplementation, gestational age and clinical classification contribute to TSH and thyroid hormone levels (48).

During clinical practice conducted by the authors of the present study, it was suspected that the 2011 ATA Guidelines may include TSH and fT4 values that are too narrow and low to assess the outcome of treatment in the Chinese population; therefore, the current study aimed to test this hypothesis. By comparing the post-treated subjects with normal subjects from the non-treatment group, the data demonstrated that no 
Table V. Percentage of patients with thyroid diseases in cohort 2014 according to the two guidelines.

\begin{tabular}{|c|c|c|c|c|}
\hline \multirow[b]{2}{*}{ Group } & \multicolumn{2}{|c|}{ Percentage $[\mathrm{n}(\%)]$} & \multirow[b]{2}{*}{ Chi-square } & \multirow[b]{2}{*}{ P-value } \\
\hline & 2011 ATA & 2012 Chinese & & \\
\hline Normal & $184(22.25)$ & $651(78.72)$ & 527.47 & $<0.001$ \\
\hline Hypothyroxinemia & $408(49.33)$ & $93(11.25)$ & 284.11 & $<0.001$ \\
\hline Hypothyroidism & $111(13.42)$ & $3(0.36)$ & 109.89 & $<0.001$ \\
\hline Subclinical hypothyroidism & $100(12.09)$ & $18(2.18)$ & 61.36 & $<0.001$ \\
\hline Hyperthyroidism & $8(0.97)$ & $12(1.45)$ & 0.81 & 0.368 \\
\hline Subclinical hyperthyroidism & $13(1.57)$ & $41(4.96)$ & 15.00 & $<0.001$ \\
\hline Syndrome of gestational hyperthyroidism & $3(0.36)$ & $3(0.36)$ & 0 & 1.000 \\
\hline Other & $0(0)$ & $6(0.72)$ & 48.76 & $<0.001$ \\
\hline
\end{tabular}

Syndrome of gestational hyperthyroidism data were analyzed using Fisher's exact test (sample size <5). 2011 ATA, 2011 Guidelines of the American Thyroid Association for the Diagnosis and Management of Thyroid Disease During Pregnancy and Postpartum; 2012 Chinese, 2012 Chinese edition of Thyroid Nodules and Differentiated Thyroid Cancer Management Guidelines; n/a, not applicable.

Table VI. Percentage of patients with thyroid diseases in cohort 2014 according to the two guidelines.

\begin{tabular}{|c|c|c|c|c|c|c|c|}
\hline \multirow[b]{2}{*}{ Group } & \multirow[b]{2}{*}{$\mathrm{n}$} & \multirow[b]{2}{*}{2011 ATA } & \multicolumn{2}{|c|}{2012 Chinese } & \multirow[b]{2}{*}{ Accordance rate $(\%)$} & \multirow[b]{2}{*}{ Kappa value } & \multirow[b]{2}{*}{ P-value } \\
\hline & & & + & - & & & \\
\hline \multirow{2}{*}{ Trimester 1} & 69 & + & 37 & 0.355 & 71.01 & 0.355 & 0.012 \\
\hline & & - & 16 & 12 & & & \\
\hline \multirow[t]{2}{*}{ Trimester 2} & 116 & + & 44 & 0.144 & 51.72 & 0.144 & $<0.001$ \\
\hline & & - & 53 & 16 & & & \\
\hline \multirow[t]{2}{*}{ Trimester 3} & 642 & + & 84 & 0.041 & 33.18 & 0.041 & $<0.001$ \\
\hline & & - & 417 & 129 & & & \\
\hline \multirow[t]{2}{*}{ Total } & 827 & + & 165 & 0.074 & 38.94 & 0.074 & $<0.001$ \\
\hline & & - & 486 & 157 & & & \\
\hline
\end{tabular}

2011 ATA, 2011 Guidelines of the American Thyroid Association for the Diagnosis and Management of Thyroid Disease During Pregnancy and Postpartum; 2012 Chinese, 2012 Guidelines for the Diagnosis and Treatment of Thyroid Disease During Pregnancy and Postpartum.

differences in pregnancy outcomes and complications were identified in spite of thyroid hormone level improvement, according to the 2011 ATA Guidelines. These data suggests that the reference TSH level in the 2011 ATA Guidelines (25th and 75th percentiles are 0.1 and $2.5 \mathrm{mIU} / 1$, respectively) may be too narrow and low to assess the outcome of treatment. Therefore, the authors of the current study hypothesized that the 2012 Chinese Guidelines could be better due to the wider normal TSH range (25th and 75th percentiles are 0.05 and $5.17 \mathrm{mIU} / \mathrm{l})$. This conclusion may help to optimize and establish evidence-based clinical guidelines for the management of thyroid disorders that would be useful to generalist and subspeciality physicians, and others providing care for Chinese patients. The current study may provide evidence for the hypothesis that the existing guidelines require revision to accommodate the Asian/Chinese population.

There were limitations in the current study. Firstly, the current study was conducted in one hospital. Future studies with larger sample sizes and prospective approaches in multiple centers are warranted. Secondly, weight was not considered as a contributor of pregnancy outcomes. It has been reported that obesity can elevate serum TSH levels $(49,50)$; therefore, it is possible that $\mathrm{SCH}$ may be misdiagnosed. In addition, it may be informative for future studies to assess thyroglobulin and thyroid peroxidase antibodies to thoroughly evaluate the thyroid-autoimmunity-associated thyroidal responses during pregnancy.

Early screening of thyroid diseases during pregnancy may allow L-T4 intervention to improve thyroid levels and decrease several adverse pregnancy outcomes and complications. The current study suggested that diagnosis of thyroid diseases exhibits regional specificity and that existing guidelines require modifications to accommodate the Asian/Chinese population.

\section{Acknowledgements}

Not applicable. 


\section{Funding}

The current study was funded by the Hunan Science and Technology Department (grant no. 2012FJ4072) and the Hunan Health and Family Planning Commission (grant no. C2015-003).

\section{Availability of data and materials}

All data generated or analyzed during this study are included in this published article.

\section{Authors' contributions}

MZ and MW conceived and designed; MZ, JL, XL and ML performed the experiments and analyzed the data. ML and $\mathrm{XL}$ wrote the manuscript. All authors critically revised and approved the final manuscript.

\section{Ethics approval and consent to participate}

The current study was approved by the institutional review board of Central South University. All patients provided written informed consent.

\section{Patient consent for publication}

All patients provided written informed consent for publication.

\section{Competing interests}

The authors declare that they have no competing interests.

\section{References}

1. Allan WC, Haddow JE, Palomaki GE, Williams JR, Mitchell ML, Hermos RJ, Faix JD and Klein RZ: Maternal thyroid deficiency and pregnancy complications: Implications for population screening. J Med Screen 7: 127-130, 2000.

2. Khan I, Okosieme OE and Lazarus JH: Current challenges in the pharmacological management of thyroid dysfunction in pregnancy. Expert Rev Clin Pharmacol 10: 97-109, 2017.

3. Rotondi M, Chiovato L, Pacini F, Bartalena L and Vitti P: Management of subclinical hypothyroidism in pregnancy: A comment from the italian society of endocrinology (SIE) and the italian thyroid association (AIT) to the 2017 ATA guidelines. 'The Italian Way'. Thyroid 28: 551-555, 2018.

4. American College of Obstetrics and Gynecology: ACOG practice bulletin. Perinatal care at the threshold of viability. Number 38, September 2002. American College of Obstetrics and Gynecology. Int J Gynaecol Obstet 79: 181-188, 2002.

5. Delitala AP, Capobianco G, Cherchi PL, Dessole S and Delitala G: Thyroid function and thyroid disorders during pregnancy: A review and care pathway. Arch Gynecol Obstet 299: 327-338, 2019.

6. Vulsma T, Gons MH and de Vijlder JJ: Maternal-fetal transfer of thyroxine in congenital hypothyroidism due to a total organification defect or thyroid agenesis. N Engl J Med 321: 13-16, 1989.

7. Su PY, Huang K, Hao JH, Xu YQ, Yan SQ, Li T, Xu YH and Tao FB: Maternal thyroid function in the first twenty weeks of pregnancy and subsequent fetal and infant development: A prospective population-based cohort study in China. J Clin Endocrinol Metab 96: 3234-3241, 2011.

8. Medenica S, Nedeljkovic O, Radojevic N, Stojkovic M, Trbojevic B and Pajovic B: Thyroid dysfunction and thyroid autoimmunity in euthyroid women in achieving fertility. Eur Rev Med Pharmacol Sci 19: 977-987, 2015.
9. Casey BM and Leveno KJ: Thyroid disease in pregnancy. Obstet Gynecol 108: 1283-1292, 2006.

10. Noten AM, Loomans EM, Vrijkotte TG, van de Ven PM, van Trotsenburg AS, Rotteveel J, van Eijsden M and Finken MJ: Maternal hypothyroxinaemia in early pregnancy and school performance in 5-year-old offspring. Eur J Endocrinol 173: 563-571, 2015.

11. Williams FL, Watson J, Ogston SA, Visser TJ, Hume R and Willatts P: Maternal and umbilical cord levels of T4, FT4, TSH, $\mathrm{TPOAb}$, and $\mathrm{TgAb}$ in term infants and neurodevelopmental outcome at 5.5 years. J Clin Endocrinol Metab 98: 829-838, 2013.

12. Li Y, Shan Z, Teng W, Yu X, Li Y, Fan C, Teng X, Guo R, Wang H, Li J, et al: Abnormalities of maternal thyroid function during pregnancy affect neuropsychological development of their children at 25-30 months. Clin Endocrinol (Oxf) 72: 825-829, 2010.

13. Berbel P, Mestre JL, Santamaria A, Palazón I, Franco A, Graells M, González-Torga A and de Escobar GM: Delayed neurobehavioral development in children born to pregnant women with mild hypothyroxinemia during the first month of gestation: The importance of early iodine supplementation. Thyroid 19: 511-519, 2009.

14. Behrooz HG, Tohidi M, Mehrabi Y, Behrooz EG, Tehranidoost M and Azizi F: Subclinical hypothyroidism in pregnancy: Intellectual development of offspring. Thyroid 21: 1143-1147, 2011.

15. Casey BM, Dashe JS, Wells CE, McIntire DD, Leveno KJ and Cunningham FG: Subclinical hyperthyroidism and pregnancy outcomes. Obstet Gynecol 107: 337-341, 2006.

16. Gilbert EW, Tay CT, Hiam DS, Teede HJ and Moran LJ: Comorbidities and complications of polycystic ovary syndrome: An overview of systematic reviews. Clin Endocrinol (Oxf) 89: 683-699, 2018.

17. Stagnaro-Green A, Abalovich M, Alexander E, Azizi F, Mestman J, Negro R, Nixon A, Pearce EN, Soldin OP, Sullivan S, et al: Guidelines of the american thyroid association for the diagnosis and management of thyroid disease during pregnancy and postpartum. Thyroid 21: 1081-1125, 2011.

18. Weiping T, Tao D, Guang N, Huixia Y and ZHengpei Z: Guidelines for the diagnosis and treatment of thyroid disease during pregnancy and postpartum. Chin J Endocrinol Metab 25: 2012.

19. Ya M: Interpretation of the management guidelines for patients with thyroid nodules and differentiated thyroid cancer (2012 Chinese edition). Lin Chuang Er Bi Yan Hou Tou Jing Wai Ke Za Zhi 27: 917-920, 2013 (In Chinese)

20. Habimana L, Twite KE, Daumerie C, Wallemacq P, Donnen P, Kalenga MK and Robert A: High prevalence of thyroid dysfunction among pregnant women in lubumbashi, democratic republic of congo. Thyroid 24: 568-575, 2014.

21. Casey BM, Thom EA, Peaceman AM, Varner MW, Sorokin Y, Hirtz DG, Reddy UM, Wapner RJ, Thorp JM Jr, Saade G, et al: Treatment of subclinical hypothyroidism or hypothyroxinemia in pregnancy. N Engl J Med 376: 815-825, 2017.

22. Alexander EK, Pearce EN, Brent GA, Brown RS, Chen H, Dosiou C, Grobman WA, Laurberg P, Lazarus JH, Mandel SJ, et al: 2017 Guidelines of the american thyroid association for the diagnosis and management of thyroid disease during pregnancy and the postpartum. Thyroid 27: 315-389, 2017.

23. Jianxin L, Shen W, zhongyan S, Weiwei W and Weiping T: The relationship between thyroid dysfunction and pregnancy outcomes in pregnant women. Chin J Endocrinol Metab 30: 1058-1062, 2014.

24. Shan $\mathrm{Z}$ and Teng W: Reflections on the iodine nutrition status of pregnancy women in iodine sufficient areas. Zhonghua Nei Ke Za Zhi 54: 4-5, 2015 (In Chinese).

25. Zhang Y, Wang H, Pan X, Teng W and Shan Z: Patients with subclinical hypothyroidism before 20 weeks of pregnancy have a higher risk of miscarriage: A systematic review and meta-analysis. PLoS One 12: e0175708, 2017.

26. Gui S: Population growth and sustainable development in China. China Popul Today 15: 26,14, 1998.

27. Zong Z, Huang J, Sun X, Mao J, Shu X and Hearst N: Prenatal care among rural to urban migrant women in China. BMC Pregnancy Childbirth 18: 301, 2018.

28. Apostolopoulou M, Savopoulos C, Michalakis K, Coppack S, Dardavessis T and Hatzitolios A: Age, weight and obesity. Maturitas 71: 115-119, 2012.

29. Heiat A: Impact of age on definition of standards for ideal weight. Prev Cardiol 6: 104-107, 2003. 
30. Gong X, Liu A, Li Y, Sun H, Li Y, Li C, Yu X, Fan C, Shan Z and Teng $\mathrm{W}$ : The impact of isolated maternal hypothyroxinemia during the first and second trimester of gestation on pregnancy outcomes: An intervention and prospective cohort study in China. J Endocrinol Invest 2018.

31. Chen S, Zhou X, Zhu H, Yang H, Gong F, Wang L, Zhang M, Jiang Y, Yan C, Li J, et al: Preconception TSH and pregnancy outcomes: A population-based cohort study in 184611 women. Clin Endocrinol (Oxf) 86: 816-824, 2017.

32. Yang H, Shao M, Chen L, Chen Q, Yu L, Cai L, Lin Z, Zhang C and $\mathrm{Lu} \mathrm{X}$ : Screening strategies for thyroid disorders in the first and second trimester of pregnancy in China. PloS one 9: e99611, 2014.

33. Ju R, Lin L, Long Y, Zhang J and Huang J: Clinical efficacy of therapeutic intervention for subclinical hypothyroidism during pregnancy. Genet Mol Res 15: 2016.

34. Stagnaro-Green A and Rovet J: Maternal thyroid function in pregnancy - a tale of two tails. Nat Rev Endocrinol 12: 110, 2016.

35. Glinoer D: The regulation of thyroid function in pregnancy: Pathways of endocrine adaptation from physiology to pathology. Endocr Rev 18: 404-433, 1997.

36. Yazbeck CF and Sullivan SD: Thyroid disorders during pregnancy. Med Clin North Am 96: 235-256, 2012

37. De Groot L, Abalovich M, Alexander EK, Amino N, Barbour L, Cobin RH, Eastman CJ, Lazarus JH, Luton D, Mandel SJ, et al: Management of thyroid dysfunction during pregnancy and postpartum: An endocrine society clinical practice guideline. J Clin Endocrinol Metab 97: 2543-2565, 2012.

38. Abalovich M, Gutierrez S, Alcaraz G, Maccallini G, Garcia A and Levalle O: Overt and subclinical hypothyroidism complicating pregnancy. Thyroid 12: 63-68, 2002.

39. Sarkar S and Bischoff LA: Management of hyperthyroidism during the preconception phase, pregnancy, and the postpartum period. Semin Reprod Med 34: 317-322, 2016.

40. Rytter D, Andersen SL, Bech BH, Halldorsson TI, Henriksen TB, Laurberg P and Olsen SF: Maternal thyroid function in pregnancy may program offspring blood pressure, but not adiposity at 20 y of age. Pediatr Res 80: 7-13, 2016.

41. Negro R, Schwartz A, Gismondi R, Tinelli A, Mangieri T and Stagnaro-Green A: Universal screening versus case finding for detection and treatment of thyroid hormonal dysfunction during pregnancy. J Clin Endocrinol Metab 95: 1699-1707, 2010.
42. Kasatkina EP, Samsonova LN, Ivakhnenko VN, Ibragimova GV, Ryabykh AV, Naumenko LL and Evdokimova YA: Gestational hypothyroxinemia and cognitive function in offspring. Neurosci Behav Physiol 36: 619-624, 2006.

43. Radetti G, Gentili L, Paganini C, Oberhofer R, Deluggi I and Delucca A: Psychomotor and audiological assessment of infants born to mothers with subclinical thyroid dysfunction in early pregnancy. Minerva Pediatr 52: 691-698, 2000.

44. Sahajpal R, Ahmed RA, Hughes CA and Foisy MM: Probable interaction between levothyroxine and ritonavir: Case report and literature review. Am J Health Syst Pharm 74: 587-592, 2017.

45. Lazarus JH, Bestwick JP, Channon S, Paradice R, Maina A, Rees R, Chiusano E, John R, Guaraldo V, George LM, et al: Antenatal thyroid screening and childhood cognitive function. $\mathrm{N}$ Engl J Med 366: 493-501, 2012.

46. Vigone MC, Di Frenna M, Guizzardi F, Gelmini G, de Filippis T, Mora S, Caiulo S, Sonnino M, Bonomi M, Persani L and Weber G: Mild TSH resistance: Clinical and hormonal features in childhood and adulthood. Clin Endocrinol (Oxf) 87: 587-596, 2017.

47. Arslan A, Bas VN, Uytun S and Poyrazoglu HG: Effects of L-thyroxine treatment on heart functions in infants with congenital hypothyroidism. J Pediatr Endocrinol Metab 30: 557-560, 2017.

48. Hirsch D, Levy S, Nadler V, Kopel V, Shainberg B and Toledano Y: Pregnancy outcomes in women with severe hypothyroidism. Eur J Endocrinol 169: 313-320, 2013.

49. Santos MI, Limbert C, Marques FC, Rosario F and Lopes L: Childhood obesity, thyroid function, and insulin resistance - is there a link? A longitudinal study. J Pediatr Endocrinol Metab 28: 557-562, 2015.

50. Bilgin $\mathrm{H}$ and Pirgon O: Thyroid function in obese children with non-alcoholic fatty liver disease. J Clin Res Pediatr Endocrinol 6: 152-157, 2014.

This work is licensed under a Creative Commons Attribution-NonCommercial-NoDerivatives 4.0 International (CC BY-NC-ND 4.0) License. 